\title{
Surgical Apgar score predicts postoperative complications after surgery for gastric cancer
}

Takanobu Yamada $^{1 *}$, Akira Tsuburaya ${ }^{2}$, Tsutomu Hayashi ${ }^{1}$, Toru Aoyama ${ }^{1}$, Hirohito Fujikawa ${ }^{1}$, Junya Shirai ${ }^{1}$, Haruhiko Cho ${ }^{1}$, Yasushi Rino $^{2}$, Munetaka Masuda ${ }^{2}$ and Takaki Yoshikawa ${ }^{1}$

${ }^{1}$ Department of Gastrointestinal Surgery, Kanagawa Cancer Center, 1-1-2 Nakao, Asahi-ku, Yokohama-shi, Kanagawa-ken 241-0815, Japan

${ }^{2}$ Department of Surgery, Yokohama City University, 3-9 Fukuura Kanazawa-ku, Yokohama Kanagawa 236-0004, Japan

\begin{abstract}
Aim: Complete surgical resection plays the most important role in the cure of gastric cancer, although surgery for gastric cancer remains a high-risk procedure. Prediction of postoperative complications thus plays an important role in gastric cancer treatment. The aim of this study was to evaluate whether the Surgical Apgar Score (SAS) can predict the risk of complications after gastrectomy.

Method: We retrospectively compared clinical characteristics, surgical factors, and oncological factors between patients with and those without postoperative complications. Multivariate logistic-regression analysis was used to assess predictors of postoperative complications.

Results: The study group comprised 190 patients who underwent gastrectomy. Grade 2 or higher complications developed in 20 patients (10.5\%). Total gastrectomy and an SAS of $\leq 6$ were significantly more frequent among patients with complications, and these factors were identified to be independent predictors of postoperative complications. The odds ratio of an SAS of $\leq 6$ was 3.606 ( $95 \%$ confidence interval, 1.080-12.020; $\mathrm{p}=0.037$ ).
\end{abstract}

Conclusions: SAS is a useful predictor of complications after surgery for gastric cancer.

\section{Introduction}

Gastric Cancer (GC) is the third most common cause of cancerrelated death in the world, and 723,027 patients are estimated to have died from this disease in 2012 [1]. Complete surgical resection plays the most important role in the cure of gastric cancer, although surgery for gastric cancer remains a high-risk procedure. Morbidity from radical gastrectomy ranges from $9 \%$ to $46 \%$ [2-6]. Recently, several large phase III trials have demonstrated that adjuvant chemotherapy, adjuvant chemoradiotherapy, and perioperative chemotherapy improves survival in patients with locally advanced GC [7-10]. However, postoperative complications sometimes delay or lead to the discontinuation of such postoperative therapy and can negatively affect patients' quality of life and survival. Therefore, the prediction of postoperative complications has an important role in gastric cancer treatment.

Previously, several scoring systems were used to predict the risk of postoperative complications. However, systems such as the Physiologic and Operative Severity Score for the Enumeration of Mortality (POSSUM), the National Surgical Quality Improvement Programme (NSQIP), and the Estimation of Physiologic Ability and Surgical Stress (E-PASS) require complex calculations based on too many perioperative variables, making them inappropriate for clinical practice [11]. Another drawback is that these tools cannot evaluate the physical response to surgical stress during operation.

Gawande et al. [12] developed and validated the surgical Apgar score (SAS) and demonstrated that SAS can be useful for rating the condition of patients after general or vascular surgery. SAS is based on intraoperative blood loss, blood pressure, and heart rate [12]. The score is very simple and easy to calculate and can be available immediately after surgery. However, the value of such a simple and useful tool for predicting postoperative complications remains to be fully confirmed in patients who undergo gastric surgery. We evaluated whether SAS can predict the risk of postoperative complications after gastrectomy.

\section{Methods}

\section{Patients}

We retrospectively studied consecutive patients with gastric adenocarcinoma who underwent elective gastrectomy in the Department of Gastrointestinal Surgery, Kanagawa Cancer Center from November 2008 through December 2009. Patients with other types of cancer were excluded.

\section{Data collection}

All data were retrieved from the patients' clinical records. The $7^{\text {th }}$ edition of the International Union against Cancer (UICC) TNM classification of malignant tumors was used for tumor staging [13]. The following data were extracted: gender, age, American Society of Anesthesiologists Physical Status (ASA-PS), comorbidity, type of surgery, surgical approach, extent of lymph-node dissection, operation time, estimated blood loss, complications, depth of tumor invasion

Correspondence to: Dr. Takanobu Yamada, Department of Gastrointestinal Surgery, Kanagawa Cancer Center, 2-3-2 Nakao, Asahi-ku, Yokohama-shi, Kanagawa-ken, 241-8515, Japan, Tel: +81 45520 2222; Fax: +81 45520 2215; E-mail: takay0218@yahoo.co.jp

Key words: gastric cancer, surgery, postoperative complication, surgical Apgar score

Received: August 27, 2015; Accepted: September 25, 2015; Published: September 30, 2015 
(pT category), lymph-node status (pN category), presence or absence of distant metastases (pM category), pathological TNM stage (pStage) [13], and SAS.

\section{Surgical Apgar score}

SAS is calculated from the estimated blood loss, lowest mean arterial pressure, and lowest heart rate. The score is the sum of the points from each category (Table 1).

\section{Complications}

Complications were defined as grade 2 or higher complications according to the Clavien-Dindo classification that occurred within 30 days after surgery [14].

\section{Ethics}

This study, a retrospective analysis, was approved by the institutional review board of Kanagawa Cancer Center. Informed consent for using the clinical data without disclosing any personal information was obtained from all patients before surgery.

\section{Statistical analysis}

We compared patients with postoperative complications with those without postoperative complications. The groups were compared with the use of the $\chi^{2}$ test for binary data. We set the cutoff value for the SAS between 6 and 7 points $[12,15]$. The cutoff values for operation time and estimated blood loss were set at the medians. We assessed predictors of postoperative complications with the use of multivariate logistic-regression analysis, including all assessed factors. All data analyses were carried out using SPSS version 20 for Windows (SPSS Inc., Chicago, IL, USA). Two-sided P values were calculated, and a difference was considered statistically significant at $\mathrm{P}<0.05$.

\section{Results}

A total of 191 patients were identified during the study period. Complete medical records were not available for 1 patient. Thus, 190 patients were assessed in this study (Figure 1).

\section{Patient clinicopathological characteristics}

There was no significant difference between patients with complications and those without complications in gender, age, ASA-PS, number of comorbidities, surgical approach, lymph-node dissection, operation time, $\mathrm{pT}$ category, $\mathrm{pN}$ category, $\mathrm{pM}$ category, or pStage. Total gastrectomy and an SAS of $\leq 6$ were significantly more common among patients who had complications (Table 2).

\section{Complications}

Grade 2 or higher complications developed in 20 patients (10.5\%). Pancreatic fistula occurred in 4 patients $(2.1 \%)$, obstruction in 4 patients $(2.1 \%)$, anastomosis leakage in 3 patients $(1.5 \%)$, anemia in 3 patients (1.5\%), postoperative bleeding in 2 patients $(1.0 \%)$, abdominal abscess in 1 patient $(0.5 \%)$, lymphorrhea in 1 patient $(0.5 \%)$, cholangitis in 1 patient $(0.5 \%)$, and ascites in 1 patient $(0.5 \%)$ (Table 3$)$.

Table 1. Surgical Apgar Score.

\begin{tabular}{|l|l|l|l|l|l|}
\hline & 0 points & $\mathbf{1}$ point & $\mathbf{2}$ points & $\mathbf{3}$ points & $\mathbf{4}$ points \\
\hline Estimated blood loss (ml) & $>1,000$ & $601-1000$ & $101-600$ & $\leq 100$ & - \\
\hline $\begin{array}{l}\text { Lowest mean arterial pressure } \\
\text { (mmHg) }\end{array}$ & $<40$ & $40-54$ & $55-69$ & $\geq 70$ & - \\
\hline Lowest heart rate (beats/min.) & $>85$ & $76-85$ & $66-75$ & $56-65$ & $\leq 55$ \\
\hline
\end{tabular}

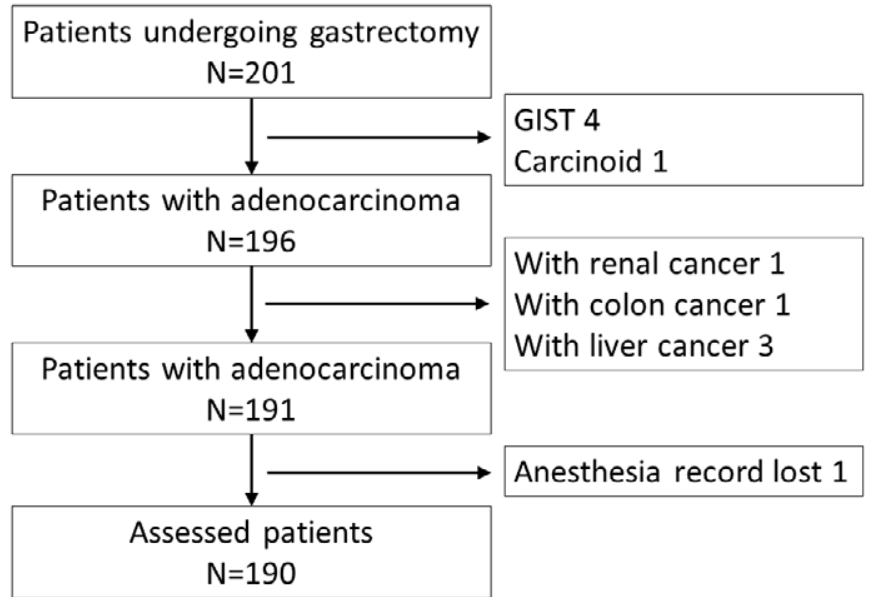

Figure 1. Consort diagram. GIST gastrointestinal stromal tumor.

Table 2. Patients clinicopathological characteristics.

\begin{tabular}{|c|c|c|c|c|}
\hline \multicolumn{2}{|c|}{ Factors } & \multirow{2}{*}{\begin{tabular}{|c|}
$\begin{array}{c}\text { Patients } \\
\text { with } \\
\text { complication } \\
\text { n (\%) }\end{array}$ \\
$15(75)$
\end{tabular}} & \multirow{2}{*}{$\begin{array}{c}\begin{array}{c}\text { Patients } \\
\text { without } \\
\text { complication } \\
\text { n (\%) }\end{array} \\
118(69)\end{array}$} & \multirow{2}{*}{\begin{tabular}{|c|}
$p$ value \\
0.797 \\
\end{tabular}} \\
\hline Gender & Male & & & \\
\hline & Female & $5(25)$ & $52(31)$ & \\
\hline \multirow[t]{2}{*}{ Age } & $<75$ & $18(90)$ & $137(81)$ & 0.540 \\
\hline & $\geq 75$ & $2(10)$ & $33(19)$ & \\
\hline \multirow[t]{2}{*}{ ASA-PS } & 1 & $7(35)$ & $65(38)$ & 1.000 \\
\hline & 2 & $13(65)$ & $105(62)$ & \\
\hline \multirow[t]{3}{*}{ Number of comorbidities } & None & $11(55)$ & $82(48)$ & 0.848 \\
\hline & 1 & $7(35)$ & $68(40)$ & \\
\hline & $\geq 2$ & $2(10)$ & $20(12)$ & \\
\hline \multirow[t]{2}{*}{ Type of surgery } & Total gastrectomy & $16(80)$ & $66(39)$ & 0.001 \\
\hline & Distal gastrectomy & $4(20)$ & $104(61)$ & \\
\hline \multirow[t]{2}{*}{ Surgical approach } & Open & $13(65)$ & $86(51)$ & 0.246 \\
\hline & Laparoscopic & $7(35)$ & $84(49)$ & \\
\hline \multirow[t]{2}{*}{ Lymph node dissection } & $<\mathrm{D} 2$ & $9(45)$ & $103(61)$ & 0.230 \\
\hline & $\geq \mathrm{D} 2$ & $11(55)$ & $67(39)$ & \\
\hline \multirow[t]{2}{*}{ Operation time (min.) } & $\geq 187$ & $13(65)$ & $82(48)$ & 0.237 \\
\hline & $<187$ & $7(35)$ & $88(52)$ & \\
\hline \multirow[t]{2}{*}{ Estimated blood loss (ml) } & $\geq 96$ & $14(70)$ & $81(48)$ & 0.096 \\
\hline & $<96$ & $6(30)$ & $89(52)$ & \\
\hline \multirow[t]{2}{*}{ Surgical Apgar score } & $\geq 7$ & $10(50)$ & $138(81)$ & 0.003 \\
\hline & $\leq 6$ & $10(50)$ & $32(19)$ & \\
\hline \multirow[t]{4}{*}{ pT category } & $\mathrm{T} 1$ & $10(50)$ & $92(54)$ & 0.538 \\
\hline & $\mathrm{T} 2$ & $1(5)$ & $23(14)$ & \\
\hline & T3 & $2(10)$ & $16(9)$ & \\
\hline & $\mathrm{T} 4$ & $7(35)$ & $39(23)$ & \\
\hline \multirow[t]{4}{*}{ pN category } & N0 & $9(45)$ & $109(64)$ & 0.353 \\
\hline & N1 & $4(20)$ & $23(14)$ & \\
\hline & $\mathrm{N} 2$ & $3(15)$ & $12(7)$ & \\
\hline & N3 & $4(20)$ & $26(15)$ & \\
\hline \multirow[t]{2}{*}{ pM category } & M0 & $19(95)$ & $155(91)$ & 1.000 \\
\hline & M1 & $1(5)$ & $15(9)$ & \\
\hline \multirow[t]{4}{*}{ pStage } & I & $8(40)$ & $91(54)$ & 0.128 \\
\hline & II & $1(5)$ & $21(12)$ & \\
\hline & III & $10(50)$ & $43(25)$ & \\
\hline & IV & $1(5)$ & $15(9)$ & \\
\hline
\end{tabular}

Complications were defined as grade 2 or higher complications according to ClavienDindo classification within 30 days after surgery.

*ASA-PS, American society of anesthesiologists physical status 
Table 3. Complication detail.

\begin{tabular}{|l|c|}
\hline Complication & $\mathbf{n}(\mathbf{\%})$ \\
\hline Pancreatic fistula & $4(2.1)$ \\
\hline Obstruction & $4(2.1)$ \\
\hline Anastomosis leakage & $3(1.5)$ \\
\hline Anemia & $3(1.5)$ \\
\hline Postoperative bleeding & $2(1.0)$ \\
\hline Abdominal abscess & $1(0.5)$ \\
\hline Lymphorrhea & $1(0.5)$ \\
\hline Cholangitis & $1(0.5)$ \\
\hline Ascites & $1(0.5)$ \\
\hline Total & $20(10.5 \%)$ \\
\hline
\end{tabular}

Table 4. Multivariate analysis.

\begin{tabular}{|c|c|c|c|c|}
\hline Factor & & Odds ratio & $95 \%$ CI & p value \\
\hline Gender $($ ref $=$ male $)$ & & 0.652 & $0.192-2.212$ & 0.492 \\
\hline Age $\geq 75$ & & 0.567 & $0.108-2.980$ & 0.502 \\
\hline ASA-PS $(\mathrm{ref}=1)$ & & 1.271 & $0.295-5.478$ & 0.748 \\
\hline \multirow[t]{3}{*}{ Number of comorbidity $(\mathrm{ref}=0)$} & & & & 0.811 \\
\hline & 1 & 0.669 & $0.158-2.843$ & 0.586 \\
\hline & 2 & 1.044 & $0.142-7.681$ & 0.966 \\
\hline Total gastrectomy & & 6.418 & $1.527-26.969$ & 0.011 \\
\hline Laparoscopic approach & & 2.222 & $0.359-13.755$ & 0.391 \\
\hline D2 lymph node dissection & & 1.631 & $0.436-6.104$ & 0.468 \\
\hline Operation time $\geq 187$ & & 1.189 & $0.317-4.454$ & 0.797 \\
\hline SAS $\leq 6$ & & 3.603 & $1.080-12.020$ & 0.037 \\
\hline Pathological stage IV & & 0.587 & $0.055-6.238$ & 0.658 \\
\hline
\end{tabular}

\section{Independent predictors of complications}

Total gastrectomy and an SAS of $\leq 6$ were identified as independent predictors for postoperative complications. The odds ratio of an SAS of $\leq 6$ was 3.606 (95\% confidence interval, $1.080-12.020 ; p=0.037$ ).

\section{Discussion}

Our results suggest that SAS predicts postoperative complications in patients undergoing surgery for gastric cancer. Risk assessment has an important role in postoperative care. If the risk is high, clinicians should revise treatment strategies to prevent or reduce complications.

In general, postoperative complications are related to surgical factors and the ability of patients to withstand stress [16,17]. However, such factors are very difficult to accurately evaluate owing to several reasons. First, surgical stress differs according to the patient, even among individuals with similar background factors who undergo the same procedure. Second, the present or absent of comorbidity does not provide a sufficient basis for estimating potential effects on the ability of patients to endure stress because the severity of comorbidity is more important. However, evaluating the severity of each comorbidity is complex and may be impossible in some patients. SAS may provide an innovative solution to these problems in a sense. SAS evaluates surgical stress on the basis of estimated blood loss and assesses the ability to withstand stress on the basis of physiological responses, such as lowest mean arterial pressure and lowest heart rate [18]. These factors seem to provide a reasonable basis for predicting the risk of postoperative complications in individual patients.

Several validation studies have reported that SAS is useful for predicting the risk of complications associated with various procedures [12,15,19-24]. In patients who underwent gastrectomy, Miki et al. [15] demonstrated that a "modified" SAS was a useful predictor of the development of severe complications. They modified the estimated blood loss score by using quartile values based on their own data set. However, estimated blood loss for the same surgical procedure differs among institutes. In fact, our median estimated blood loss was lower than theirs ( $96 \mathrm{ml} v$ s. $274 \mathrm{ml}$ ). Surgical stress as evaluated on the basis of estimated blood loss seems to be similar among different procedures [18]. From the viewpoint of general use and the surgical stress of patients, we consider the original SAS classification better than the modified version.

Our study had several limitations. This was a retrospective observational study that was performed in a single institution that specializes in cancer therapy. The validity of our results therefore must be confirmed in larger studies including a wider range of hospitals. Another limitation was that the SAS is strongly affected by the protocol for anesthesia management, such as the use of beta-blockers or epidural anesthesia. This factor might have biased our results.

A recent study has shown that postoperative intra-abdominal infectious complications adversely affect overall survival and relapsefree survival $[25,26]$. On the other hand, the SAS might be a scoring system that mirrors general physiological performance, considered an important factor in overall survival. Hence, further studies should be performed to confirm whether SAS is an accurate predictor of survival.

In conclusion, our results suggest that SAS is useful for predicting the risk of complications after surgery for gastric cancer.

\section{Acknowledgments}

This study was supported in part by Kanagawa standard anticancer therapy support system (KSATSS).

\section{References}

1. Ferlay J, Soerjomataram I, Ervik M, Dikshit R, Eser S, et al. (2013) GLOBOCAN 2012 v1.0, Cancer Incidence and Mortality Worldwide: IARC CancerBase No. 11. Lyon, France: International Agency for Research on Cancer.

2. Bonenkamp JJ, Hermans J, Sasako M, van de Velde CJ, Welvaart K, et al. (1990) Extended lymph-node dissection for gastric cancer. $N$ Engl J Med 340: 908-914. [Crossref]

3. Cuschieri A, Fayers P, Fielding J, Craven J, Bancewicz J, et al. (1996) Postoperative morbidity and mortality after D1 and D2 resections for gastric cancer: preliminary results of the MRC randomised controlled surgical trial. The Surgical Cooperative Group. Lancet 347: 995-999. [Crossref]

4. Sasako M, Sano T, Yamamoto S, Kurokawa Y, Nashimoto A, et al. (2008) D2 lymphadenectomy alone or with para-aortic nodal dissection for gastric cancer. $N E n g l$ J Med 359: 453-462. [Crossref]

5. Kim HH, Hyung WJ, Cho GS, Kim MC, Han SU, et al. (2010) Morbidity and mortality of laparoscopic gastrectomy versus open gastrectomy for gastric cancer: an interim report-a phase III multicenter,prospective, randomized trial (KLASS Trial). Ann Surg 51: 417-420. [Crossref]

6. Katai H, Sasako M, Fukuda H, Nakamura K, Hiki N, et al. (2010) Safety and feasibility of laparoscopy-assisted distal gastrectomy with suprapancreatic nodal dissection for clinical stage I gastric cancer: a multicenter phase II trial (JCOG 0703). Gastric Cancer 13: 238-244. [Crossref]

7. Sakuramoto S, Sasako M, Yamaguchi T, Kinoshita T, Fujii M, et al. (2007) Adjuvant chemotherapy for gastric cancer with S-1, an oral fluoropyrimidine. $N$ Engl $J$ Med $357: 1810-1820$.

8. Bang YJ, Kim YW, Yang HK, Chung HC, Park YK, et al. (2012) Adjuvant capecitabine and oxaliplatin for gastric cancer after D2 gastrectomy (CLASSIC): a phase 3 openlabel, randomised controlled trial. Lancet 379: 315-321. [Crossref]

9. Macdonald JS, Smalley SR, Benedetti J, Hundahl SA, Estes NC, et al. (2001) 
Chemoradiotherapy after surgery compared with surgery alone for adenocarcinoma of the stomach or gastroesophageal junction. $N$ Engl J Med 345: 725-730. [Crossref]

10. Cunningham D, Allum WH, Stenning SP, Thompson JN, Van de Velde CJ, et al. (2006) Perioperative chemotherapy versus surgery alone for resectablegastroesophageal cancer. N Engl J Med 355: 11-20. [Crossref]

11. Chandra A, Mangam S, Marzouk D. (2009) A review of risk scoring systems utilised in patients undergoing gastrointestinal surgery. J Gastrointest Surg 13: 1529-1538. [Crossref]

12. Gawande AA1, Kwaan MR, Regenbogen SE, Lipsitz SA, Zinner MJ. (2007) An Apgar score for surgery. J Am Coll Surg 204: 201-208. [Crossref]

13. Sobin LH, Gospodarowicz MK, Witterkind CH. (2009) International Union Agains Cancer (UICC) TNM Classification of Malignant Tumors. 7th ed. Oxford, UK: WileyBlack-well.

14. Dindo D, Demartines N, Clavien PA (2004) Classification of surgical complications: a new proposal with evaluation in a cohort of 6336 patients and results of a survey. Ann Surg 240: 205-213. [Crossref]

15. Miki Y, Tokunaga M, Tanizawa Y, Bando E, Kawamura T, Terashima M (2014) Perioperative risk assessment for gastrectomy by surgical Apgar score. Ann Surg Oncol 21: 2601-2607. [Crossref]

16. Takama T, Okano K, Kondo A, Akamoto S, Fujiwara M, et al. (2015) Predictors of postoperative complications in elderly and oldest old patients with gastric cancer. Gastric Cancer 18: 653-661. [Crossref]

17. Lee KG, Lee HJ, Yang JY, Oh SY, Bard S, et al. (2014) Risk factors associated with complication following gastrectomy for gastric cancer: retrospective analysis of prospectively collected data based on the clavien-dindo system. J Gastrointest Surg 18:1269-1277. [Crossref]
18. Kato M, Honda I, Suzuki H, Murakami M, Matsukawa S, Hashimoto Y. (1998) Interleukin-10 production during and after upper abdominal surgery. $J$ Clin Anesth 10: 184-188. [Crossref]

19. Regenbogen SE, Lancaster RT, Lipsitz SR, Greenberg CC, Hutter MM, et al. (2008) Does the Surgical Apgar Score measure intraoperative performance? Ann Surg 248 320-328. [Crossref]

20. Prasad SM, Ferreria M, Berry AM, Lipsitz SR, Richie JP, et al. (2009) Surgical Apgar outcome score: perioperative risk assessment for radical cystectomy. J Urol 181: 10461052. [Crossref]

21. Haynes AB, Regenbogen SE, Weiser TG, Lipsitz SR, Dziekan G, et al. (2011) Surgica outcome measurement for a global patient population: validation of the Surgical Apgar Score in 8 countries. Surgery 149: 519-524. [Crossref]

22. Regenbogen SE, Ehrenfeld JM, Lipsitz SR, Greenberg CC, Hutter MM, et al. (2009) Utility of the surgical apgar score: validation in 4119 patients. Arch Surg 144: 30-36. [Crossref]

23. Zighelboim I, Kizer N, Taylor NP, Case AS, Gao F, et al. (2010) "Surgical Apgar Score" predicts postoperative complications after cytoreduction for advanced ovarian cancer. Gynecol Oncol 116: 370-373. [Crossref]

24. Regenbogen SE, Bordeianou L, Hutter MM, Gawande AA (2010) The intraoperative Surgical Apgar Score predicts postdischarge complications after colon and rectal resection. Surgery 148: 559-566. [Crossref]

25. Tokunaga M, Tanizawa Y, Bando E, Kawamura T, Terashima M (2014) Poor survival rate in patients with postoperative intra-abdominal infectious complications following curative gastrectomy for gastric cancer. Ann Surg Oncol 20: 1575-1583. [Crossref]

26. Hayashi T, Yoshikawa T, Aoyama T, Hasegawa S, Yamada T, et al. (2015) Impact of infectious complications on gastric cancer recurrence. Gastric Cancer 18: 368-374.

Copyright: $\odot 2015$ Yamada T. This is an open-access article distributed under the terms of the Creative Commons Attribution License, which permits unrestricted use, distribution, and reproduction in any medium, provided the original author and source are credited. 